\title{
Conceptual development of a novel photovoltaic-thermoelectric system and preliminary economic analysis
}

\author{
Guiqiang $\mathrm{Li}^{1 *}$, Xudong Zhao ${ }^{2 *}, \mathrm{Jie} \mathrm{Ji}^{1}$ \\ ${ }^{1}$ Department of Thermal Science and Energy Engineering, University of Science and \\ Technology of China, 96 Jinzhai Road, Hefei City, 230026, China; \\ ${ }^{2}$ School of Engineering, University of Hull, Hull HU6 7RX, UK
}

Abstract:

Photovoltaic-thermoelectric (PV-TE) hybrid system is one typical electrical production based on the solar wide-band spectral absorption. However the PV-TE system appears to be economically unfeasible owing to the significantly higher cost and lower power output. In order to overcome this disadvantage, a novel PV-TE system based on the flat plate micro-channel heat pipe was proposed in this paper. The mathematic model was built and the performance under different ambient conditions was analyzed. In addition, the annual performance and the preliminary economic analysis of the new PV-TE system was also made to compare to the conventional PV system. The results showed that the new PV-TE has a higher electrical output and economic performance.

Keywords: Photovoltaic-thermoelectric, micro-channel heat pipe, mathematic model, economic analysis 
*Corresponding authors. Tel/Fax: +86 551 63603512. E-mail: ligq@mail.ustc.edu.cn (G. Li); Xudong.zhao@hull.ac.uk (X.Zhao)

\section{Introduction}

Solar power generation is one of the important applications for solar energy, and the low cost and high efficiency solar power generation has always been the focus of the solar energy basic research. Currently, Photovoltaic (PV) is the most common and commercialized way for solar electrical generation. Nevertheless, the conventional materials can convert effectively only photons of energy close to the semiconductor band gap [1]. For example, the single junction $\mathrm{Si}$ technologies are limited to maximum efficiencies in the order of $30 \%$ [2], which leads to most of the absorbed energy is converted into the thermal energy, increasing the PV temperature and leading to further efficiency reduction [3], [4] and [5]. Thus the way to utilize the thermal energy to produce the electricity is important for fully exploiting the wide solar spectrum.

Thermoelectric generation (TEG) is a device to utilize the Seebeck effect to convert heat from solar energy directly into electrical energy through the movement of charge carriers induced by a temperature span across it [6]. Compared to conventional electrical power generator systems, the TEG theoretically can own many advantages such as being simple and highly reliable, having no moving parts, and being environmentally friendly. From the view of the fully solar spectrum application and the installment convenience, it would be suitable for combination the PV and TE. 
Many researchers paid more attentions on the combination of the thermoelectric and the photovoltaic technology in a hybrid system in recent years [7], [8], [9] and [10]. There are main two types: splitting system and integrating system. Kraemer et al proposed a general optimization methodology of solar spectrum splitting for PV-TE system [11]. Mizoshiri et al used thin-film thermoelectric modules to combine with photovoltaic [12]. Fleurial indicated that the PV-TE may be integrated with the solar concentrator, which can obtain a high electrical output [13]. Van Sark predicted the feasibility of the splitting PV-TEG that the efficiency can be enhanced up to $23 \%$, however the heat losses has been neglected in the simulation [14]. Hashim et al built the model for geometry optimisation of thermoelectric devices in a hybrid PV-TE system [15]. Bjørk and Nielsen analyzed the performance of a combined solar photovoltaic (PV) and thermoelectric generator (TEG) device [16]. Lin et al coupled the temperatures and power outputs in hybrid photovoltaic and thermoelectric modules [17]. Da et al studied the light trapping to solar energy utilization for a novel photovoltaic-thermoelectric hybrid system to fully utilize solar spectrum [18]. Cui et al designed a novel concentrating photovoltaic-thermoelectric system incorporated with phase change materials [19]. Wang et al took the experiment on the high-performance photovoltaic-thermoelectric hybrid device using the dye-sensitised solar cell [20].

However, whatever the splitting system or integrating system, the pair-arrangement between the PV and TE modules appears to be economically unfeasible, owing to the significantly higher cost and lower power output of the TE 
module relative to the PV module.

Heat pipes are efficient heat transfer devices that utilize latent heat of vaporization to transport heat over a long distance with small temperature gradient [21]. Micro-channel heat pipe (MCHP) has a higher heat transfer and smaller temperature gradient performance due to the micro-channel structure [22]. Li et al made the experiment and simulation on the solar thermoelectric generator using the micro-channel heat pipe array, and the system saved a mass of TEG modules and reduced lots of the cost which showed the significant advantage than the TE without the heat pipe in series [23]. In addition, the non-uniform temperature can seriously affect the efficiency of the PV and TEG [24], [25]. Thus, combing the flat plate micro-channel heat pipe and PV and TE, can homogenize the heat flux distribution for the high electrical output. At the same time, the flat plate micro-channel heat pipe can be attached to PV and TE closely, which can further reduce the contact thermal resistance between them.

Therefore, in this paper the conceptual of a novel photovoltaic-thermoelectric system was developed, which included the PV, the micro-channel heat pipe, the TE and the heat sink. The different ambient parameters were all considered to analyze the system performance. Furthermore, the conventional PV system was introduced to compare to the new PV-TE system. In addition, the preliminary economic analysis was carried out based on the whole year performance evaluation.

\section{System description}


The novel photovoltaic-thermoelectric system was shown in Fig.1. The PV modules were attached to the upper surface of the evaporator of the MCHP while the TE modules were attached to the lower surface of the condenser. During operation, the solar energy imposed on PV modules on the upper surface of the MCHP's evaporator, then the thermal energy was conveyed to MCHP's condenser, by means of the evaporation of the working fluid within the MCHP. In the condenser, the heat was released via condensation of the MCHP working fluid and was then transferred to the attached TE modules. This created a temperature gradient across the TE module, thus resulting in a thermal to electrical conversion by means of the 'Peltier effect'. The cooling structure of TEG was air cooling, whose performance was decided by the cooling structure, the ambient temperature and the wind speed.

\section{Mathematic model}

The heat transfer process of the new PV-TE system was shown in Fig.2. According to heat balance, the energy conducted by the heat pipe can be expressed as below,

$E_{\text {in }}=E_{p v}+E_{\mathrm{co} n}+E_{\mathrm{rad}}+E_{\mathrm{cov}}$

Where $E_{\text {in }}$ is the solar energy absorbed by the PV-TE system. It can be expressed as below,

$E_{i n}=(\tau \alpha)_{p v} A G$

Where $(\tau \alpha)_{p v}$ and $\mathrm{A}$ are the effective transmittance-absorption product of the PV and PV area respectively. $\mathrm{G}$ is the solar radiation. 
$(\tau \alpha)_{p v}=\frac{\tau_{\alpha} \tau_{\rho} \alpha}{1-(1-\alpha) \rho_{g}}$

The electrical output is given by:

$E_{p v}=(\tau \alpha)_{p v} A G \eta_{r}\left[1-\beta_{p v}\left(T_{p}-T_{r}\right)\right]$

where $T_{p}$ is the PV temperature. $\beta_{p v}$ is the temperature coefficient of PV efficiency.

$T_{r}$ is the reference temperature.

The electrical efficiency of the PV can be expressed as:

$\eta_{s y s-p v}=\frac{E_{p v}}{A G}$

$E_{\text {rad }}$ is the energy transferred to the space via the radiation, which is expressed as below,

$E_{r a d}=h_{r a d} A\left(T_{p}-T_{s k y}\right)$

$h_{\text {rad }}$ can be defined as

$h_{\text {rad }}=\varepsilon \delta\left(T_{s k y}^{2}+T_{p}^{2}\right)\left(T_{s k y}+T_{p}\right)$

$T_{s k y} \quad$ can be defined as

$T_{s k y}=0.0552 T_{a}^{1.5}$

Where $T_{p}$ is temperature of the $\mathrm{PV}$ and $T_{a}$ is the temperature of ambient air.

$E_{\text {cov }}$ is the energy convection between the PV and the ambient air, which is expressed as

$E_{c o v}=h_{c o v} A\left(T_{p}-T_{a}\right)$

where $h_{c o v}$ can be defined as

$h_{c o v}=6.5+3.3 u$

The energy conducted via the heat pipe can also be expressed in several ways. 
The heat flux pass through the thermal contact resistance between the PV and heat pipe can be expressed as,

$E_{c o n}=\left(T_{p}-T_{h}\right) / R_{c t 1}$

where $T_{h}$ is the temperature of the evaporating side of the heat pipe.

The heat flux conducted by the heat pipe can be expressed as,

$E_{c o n}=K L_{h p}\left(T_{h}-T_{l}\right)$

where $\mathrm{K}$ is the thermal conductivity of the heat pipe, $L_{h p}$ is the length of the heat pipe and $T_{l}$ is the temperature of the condensate side of the heat pipe.

The heat flux pass through the thermal contact resistance between heat pipe and the TEG $\left(\mathrm{R}_{\mathrm{ct} 2}\right)$ can be defined as,

$E_{c o n}=\left(T_{l}-T_{\text {tegh }}\right) / R_{c t 2}$

where $T_{\text {tegh }}$ is the temperature of the hot side of the TEG.

The energy that passed through the hot side of the TEG can be defined by following equation.

$Q_{\text {tegh }}=2 n_{\text {teg }} \alpha_{\text {teg }} T_{\text {tegh }} I+2 n_{\text {teg }} \frac{a_{\text {teg }} k_{\text {teg }}}{l_{\text {teg }}} \Delta T-\frac{1}{2} I^{2} 2 n_{\text {teg }} \frac{r_{t e g} l_{\text {teg }}}{a_{\text {teg }}}$

Similarly, the heat through the cold side of TEG can be expressed as

$Q_{\text {tegl }}=2 n_{\text {teg }} \alpha_{\text {teg }} T_{\text {tegl }} I+2 n_{\text {teg }} \frac{a_{\text {teg }} k_{\text {teg }}}{l_{\text {teg }}} \Delta T+\frac{1}{2} I^{2} 2 n_{\text {teg }} \frac{r_{\text {teg }} l_{\text {teg }}}{a_{\text {teg }}}$

where $Q_{\text {tegh }}$ is the energy that passed in hot side of the TEG, $Q_{\text {tegl }}$ is the energy that passed in cold side of the TEG, $n_{\text {teg }}$ is the numbers of PN junction, $\alpha_{\text {teg }}$ is the Seebeck coefficient, $I$ is the current, $K_{\text {teg }}$ is thermal conductivity of TEG, $l_{\text {teg }}$ is the length of TEG, $T_{\text {tegl }}$ is the temperature of cold side of TEG, ${ }_{\text {teg }}$ is the electrical 
resistivity of a $\mathrm{P}$ or $\mathrm{N}$ leg, $a_{\text {teg }}$ is the Cross-sectional area of a $\mathrm{P}$ or $\mathrm{N}$ leg.

In a real system, TEG has to operate in the closed-circuit condition in order to deliver the power to external load. Under such circumstances, the heat flow through the TEG consists of both heat conduction and the Peltier heat. As a result, the $\Delta T$ can be replaced by Refs. [26], [27] and [28].

$\Delta T=\left(1+Z T_{M}\right)\left(T_{\text {tegh }}-T_{\text {tegl }}\right)$

Where $\mathrm{Z}\left(=\alpha_{\text {teg }}^{2} / \rho \cdot k\right)$ is the thermoelectric figure of merit, $T_{M}$ is givens as

$T_{M}=\frac{(1+2 s) T_{t e g h}+T_{t e g l}}{2(1+s)^{2}}$

Where $\mathrm{s}$ is the ratio of the load resistance to the internal resistance of the TE module.

when $s=1$, the electrical efficiency of the TEG can be expressed as:

$\eta_{\text {teg }}=\frac{Q_{\text {tegh }}-Q_{\text {tegl }}}{Q_{\text {tegh }}}$

The electrical efficiency of the system can be expresses

$\eta_{s y s-t e g}=\frac{Q_{t e g h}-Q_{\text {tegl }}}{A G}$

This heat can also be expressed as the heat flux through the heat sink attached to the cold side of TEG.

$Q_{\text {tegl }}=\left(T_{\text {tegl }}-T_{a}\right) / R_{\text {fin }}$

Where $R_{f i n}$ is the thermal resistance of the fin which clings to the cold side of TEG, and can be expressed as below,

$R_{\text {fin }}=R_{\text {conf }}+R_{\mathrm{cov} f}+R_{c t 3}$

Where $R_{\text {conf }}$ is the resistance of the heat conduction of the heat sink and $R_{c t 3}$ is the thermal contact resistance between the TEG and the heat sink. 
$R_{\text {conf }}=\frac{H}{K_{f i n} S_{1}}$

where $H$ is the height of the heat sink, $K_{f i n}$ is the thermal conductivity of the fin and $S_{1}$ is the cross section area of the heat sink.

In order to attain the value of $R_{\operatorname{cov} f}$ which is the thermal resistance of convection heat transfer between fin and ambient air, the convection heat transfer coefficient $\mathrm{h}_{\text {covf }}$ can be obtained [29].

$$
\begin{aligned}
& C_{f x}=0.0592 \mathrm{Re}_{x}^{-1 / 5} \\
& \operatorname{Re}_{x}=\frac{\rho u x}{\mu}
\end{aligned}
$$

where $u, \rho, \mu$ represent velocity, density and viscosity coefficient of the fluid respectively, $x$ is the characteristic length of the fin. $\rho=1.1614 \mathrm{~kg} \cdot \mathrm{m}^{-3}, \mu$ $=1.846^{*} 10^{-5} N \cdot s \cdot m^{-2}$.

$$
\begin{aligned}
& N u_{x}=\frac{h_{x} x}{k_{\text {air }}}=0.332 \operatorname{Re}_{x}^{\frac{1}{2}} \operatorname{Pr}^{\frac{1}{3}}, 0.6 \leq \operatorname{Pr} \leq 15 \\
& \operatorname{Pr}=\frac{v}{\alpha}=\frac{\mu C_{p}}{k_{\text {air }}}
\end{aligned}
$$

where $v$ is the kinematic viscosity, $h_{x}$ is the local heat transfer coefficient along the length of the fin, $\mathrm{k}_{a i r}$ is the thermal conductivity of air, $C_{p}$ is the specific heat capacity of air, $\alpha$ is the heat diffusivity. $v=1.589 * 10^{-5} \mathrm{~m}^{2} \cdot \mathrm{s}^{-1}, c_{p}=1.007$ $k J \cdot \mathrm{Kg}^{-1} \cdot \mathrm{K}^{-1}, \quad \alpha=2.25 * 10^{-5} \mathrm{~m}^{2} / \mathrm{s}$.

Thus $S t_{x}$ can be obtained as below,

$$
\begin{aligned}
& S t_{x}=\frac{N u_{x}}{\operatorname{Re}_{x} \operatorname{Pr}}=\frac{h_{x}}{\rho C_{p} \mu_{\infty}}=0.332 \operatorname{Re}_{x}^{-1 / 2} \operatorname{Pr}^{-2 / 3} \\
& S t_{x} \operatorname{Pr}^{2 / 3}=C_{f, x} / 2
\end{aligned}
$$


$h_{x}=\frac{C_{f, x} \rho C_{p} u_{\infty}}{2 P r^{2 / 3}}$

And the local heat transfer coefficient $h_{x}$ is obtained,

$h_{x}=\frac{0.0296 x^{-1 / 5} \rho C_{p} \mu_{\infty}^{4 / 5}}{v^{-1 / 5} \cdot \operatorname{Pr}^{2 / 3}}$

Therefore,

$h_{\text {covf }}=\frac{1}{L} \int_{0}^{L} h_{x} d x$

After finishing calculated tablet on the air, the average heat transfer coefficient can be expressed as:

$h_{\operatorname{cov} f}=\frac{0.037 L^{-1 / 5} \rho \mathrm{C}_{p} u_{\infty}^{4 / 5}}{v^{-1 / 5} \cdot \operatorname{Pr}^{2 / 3}}$

Then the thermal resistance between the radiator and the air is:

$$
R_{\operatorname{cov} f}=\frac{1}{h_{\operatorname{cov} f} S_{2}}=\frac{v^{-1 / 5} \cdot \operatorname{Pr}^{2 / 3}}{0.037 L^{-1 / 5} \rho C_{p} u_{\infty}^{4 / 5} S_{2}}
$$

Where $S_{2}$ is the total area of the fin.

Therefore the overall electrical efficiency of the PV-TEG system can be expressed as

$$
\eta_{s y s-p v t e}=\eta_{s y s-p v}+\eta_{s y s-t e g}
$$

\section{Performance analysis}

The performance of the new PV-TE system was affected by the ambient parameters. In this section, different solar radiation, wind speed and ambient temperature were all considered to illustrate the PV-TE performance. In addition, the conventional PV system was also compared to this new system. The relative parameters are shown in Table 1 . The relatively models and parameters values have 
been verified in [23], [30], [31].

\subsection{Different solar radiation}

When the wind speed was $2 \mathrm{~m} / \mathrm{s}$ and the ambient temperature was $298 \mathrm{~K}$, the TEG hot and cold side temperature was shown in Fig. 3. With the solar radiation increase, the temperature difference of TEG showed a rise tendency.

Corresponding to Fig.3, when the solar radiation was low, the temperature difference of TEG was small, thus the electrical efficiency of TEG was close to the zero (Fig.4). However, when the solar radiation was high, the electrical efficiency of TEG presented a trend of the rapid growth. On the other hand, with the hot side temperature increase, which means when the PV temperature increased, the PV electrical efficiency had a decrease tendency.

When the radiation was low, the electrical efficiency of TEG was small, so the system efficiency of TEG became lower. However, when the radiation was high, the electrical efficiency of TEG was larger, so the system efficiency of TEG became higher. Therefore with the solar radiation increased, the system efficiency of PV-TE presented the fall and then rise tendency (Fig.5). For the conventional PV system, with the solar radiation increase, the PV temperature became higher, so the system efficiency presented a decrease tendency.

\subsection{Different wind speeds}

The wind speed increased will enhance the cooling of the heat sink, which would be benefit for the TEG. Nevertheless, the larger wind speed would also increase the thermal losses on the PV via the heat convection to the environment, which will 
decrease the hot side temperature of TEG and affect the TEG electrical efficiency negatively. Therefore, the comprehensive performance needed to evaluate on the specific working condition. Fig.6 showed the variation curves of the hot and cold side temperature of TEG at different wind speeds when the solar radiation was $1000 \mathrm{~W}$ and the ambient temperature was $298 \mathrm{~K}$. It is clearly that with the wind speed increase, the temperature difference of TEG became larger and then smaller. That also indicated that the TEG output would be higher then lower.

With the different wind speeds, the electrical efficiency of PV and TEG were shown in Fig.7. The curve of the TEG electrical efficiency was in keeping with that of the temperature difference, which indicated a rise then fall tendency. For the PV efficiency, the curve presented a rising trend, but the rising amplitude became smaller, which means that when the wind speed increased to a high value, the PV electrical efficiency would be affected in a small range.

The comparison between the PV-TE and conventional PV on the system efficiency was shown in Fig.8. With the increase of the wind speed, the PV-TE system efficiency presented a rising than fall tendency. In the scope of the low wind speeds, the PV output increase was larger than the TEG output decrease. But in the scope of the high wind speed, the PV output increase was lower than the TEG output decrease, so the system efficiency decreased significantly.

\subsection{Different ambient temperature}

When the solar radiation was $1000 \mathrm{~W}$ and the wind speed was $2 \mathrm{~m} / \mathrm{s}$, the hot and cold side temperature of TEG were all raised with the ambient temperature increase 
(Fig.9). The temperature difference slightly became smaller when the ambient temperature became higher.

In the PV-TE system, the TEG electrical efficiency changed in a small scope since the variation of the temperature difference of TEG was small (Fig.10). But it is clearly that the PV electrical efficiency had a significant decrease tendency, because the PV temperature rose with the ambient temperature increase.

The variation tendency of the PV-TE system and the conventional PV system were all downward with the increase of the ambient temperature, which was due to the higher temperature led to the lower PV efficiency. However, because of the TEG output, the new PV-TE system was still higher than the conventional PV system.

\section{Annual output and preliminary economic analysis}

To predict the annual performance of the new PV-TE system, a numerical simulation program written using Matlab has been developed. The Efficiency comparison of PV, novel PV-TE and conventional PV-TE with different solar radiations was shown in Fig.12. The electrical efficiency of the conventional PV-TE is the highest one, and that of the PV is lowest one.

Fig13 showed the flow chart of the computation process for the PV-TE system. In the present simulation, the PV-TE system would collect the solar energy. The weather data were provided by EnergyPlus. The weather data in half an hour is the average value, so the weather data changes every half an hour. 
For the conventional PV-TE system, the economic advantage to the conventional PV system is existent. So the key issue in this study is that whether the proposed new PV-TE has the advantages in the efficiency and the economy than the common PV system. The annual electricity outputs of the novel PV-TE system, the conventional PV-TE system and the PV system were shown in Fig.14.

In winter, the electricity difference between the new PV-TE system and conventional PV system was lower than that in summer, which may be because the low ambient temperature was benefit for the conventional PV system. From Fig.14, it can be seen that the new PV-TE system can attain more about $6.44 \mathrm{kWh}$ annual electricity output than the conventional PV system with the same area in Hefei $\left(31^{\circ}\right.$ $\left.53^{\prime} \mathrm{N}, 117^{\circ} 15^{\prime} \mathrm{E}\right)$ in the eastern region of China. And the conventional PV-TE system can attain more about $5.40 \mathrm{kWh}$ annual electricity output than the novel PV-TE system.

From the view of the investment and return, the efficiency is just a factor, and the economic factors such as the ratio of output to input are also important. For the new PV-TE system, besides of the same PV area with the conventional PV, it has a micro-channel heat pipe, a TE module and a heat sink, and the extra costs were shown in Table 2. However, for the conventional PV-TE, due to the pair-arrangement between the PV and TE module, the extra costs is high with the same area, which can be approximately calculated ( $¥ 22 * 1.2 * 0.18 / 0.055^{2}=¥ 1570$ ), which is about 41 times higher than the extra costs of the new PV-TE. At the same time, the extra 
annually electrical production of the conventional PV-TE is just 2 times higher $((6.44$ $+5.40) / 6.44 \approx 2$ ) than that of the new PV-TE. Therefore, the new PV-TE has the economic advantage than the conventional PV-TE.

Therefore, in this section, the comparison between the new PV-TE system and the conventional PV system will be presented. The present section regards the economic analysis of the system, where the parameter concerning the electricity cost will be $¥ 1.20 / \mathrm{kWh}$. The basic methodology is deployed for the calculation of the economic performance.

The coefficient that correlates a future cash flow with a present value is called the present value coefficient and is given by the following Eq. (35).

$$
C F_{t=0}=\frac{C F_{t=0}}{(1+r)^{n}}
$$

Where $\mathrm{r}$ is the interest rate.

The net present value (NPV), which is actually the present value of the total cash flows during the economic life cycle of a system, is given next by Eq. (36).

$$
N P V=\sum_{j=1}^{n} \frac{B_{t=j}-C_{t=j}}{(1+r)^{j}}
$$

Where $B$ is the present value of the benefit; $C$ is the present value of the cost; $j$ is the time period.

The Pay-Back-Period (PBP) is the time-period in years required for the NPV to reach a zero value and is found by solving Eq. (36) with NPV $=0$. The higher NPV means the more profit during the life cycle. In this section, due to the two systems have the same area of PV, so it only needs to calculate the PBP of the extra investment. 
In this section, it is assumed that the labor and maintain costs of the new PV-TE system are the same as that of the conventional PV system. Thus the recovery cost of the extra investment will be achieve in six years (Fig.15), which means from the sixth year, the new PV-TE system has a higher ratio of output to input than the conventional PV system. Therefore, the new PV-TE system constitutes from the techno-economic aspect a more efficient solution for the power production.

\section{Conclusion}

In this paper, the conceptual development of a novel photovoltaic-thermoelectric system was presented. The performance comparison between the new PV-TE system and the conventional PV system was demonstrated under different ambient conditions. The preliminary economic analysis was also made based on NPV, which indicated that the PBP of the additional investment is approximately six years.

In conclusion, the new PV-TE system has many advantages than the conventional PV-TE system and PV system: (a) The micro-channel heat pipe can reduce the amount of TEG and save the cost significantly than the conventional PV-TE system; (b) Micro-channel heat pipe has a higher heat transfer performance than the common heat pipe, so the new system has a high heat transfer performance; (c) Flat plate structure of the micro-channel heat pipe can be lamination with the PV and TE well and reduce the contact thermal resistance significantly between them; (d) The low temperature gradient can keep a high electrical output of PV and TE; (e) Comparison with the conventional PV system, the PV-TE has the higher output 
performance and economic value.

\section{Acknowledgment}

The study was sponsored by the National Science Foundation of China (Grant Nos. 51408578, 51611130195), Anhui Provincial Natural Science Foundation (1508085QE96), Dong Guan Innovative Research Team Program (No. 2014607101008)

\section{References}

[1] D.N. Kossyvakis, G.D. Voutsinas, E.V. Hristoforou. Experimental analysis and performance evaluation of a tandem photovoltaic-thermoelectric hybrid system. Energy Conversion and Management 117 (2016) 490-500

[2] V. Avrutin, N. Izyumskaya, H. Morko. Semiconductor solar cells: recent progress in terrestrial applications. Superlatt Microstruct, 49 (4) (2011) 337-364

[3] Guiqiang Li, Gang Pei, Jie Ji, Ming Yang, Yuehong Su, Ning Xu. Numerical and experimental study on a PV/T system with static miniature solar concentrator. Solar Energy 120 (2015) 565-574

[4] Guiqiang Li, Gang Pei, Ming Yang, Jie Ji, Yuehong Su. Optical evaluation of a novel static incorporated compound parabolic concentrator with photovoltaic/thermal system and preliminary experiment. Energy Conversion and Management 85 (2014) 204-211

[5] Guiqiang Li, Gang Pei, Jie Ji, Yuehong Su. Outdoor overall performance of a 
novel air-gap-lens-walled compound parabolic concentrator (ALCPC) incorporated with photovoltaic/thermal system. Applied Energy 144 (2015) 214-223

[6] Wei He, Gan Zhang, Xingxing Zhang, Jie Ji, Guiqiang Li, Xudong Zhao. Recent development and application of thermoelectric generator and cooler. Applied Energy $143(2015) 1-25$

[7] Deng Y, Zhu W, Wang Y, Shi YM. Enhanced performance of solar-driven photovoltaic-thermoelectric hybrid system in an integrated design. Solar Energy, 2013, 88: 182-191

[8] J. Zhang, Y. Huan, L. Yuang. Performance estimation of photovoltaic thermoelectric hybrid systems. Energy, 78 (2014), pp. 895-903

[9] Y. Wu, S. Wu, L. Xiao. Performance analysis of photovoltaic-thermoelectric hybrid system with and without glass cover. Energy Convers Manage, 93 (2015), pp. $151-159$

[10] J. Lin, T. Liao, B. Lin. Performance analysis and load matching of a photovoltaic-thermoelectric hybrid system. Energy Convers Manage, 105 (2015), pp. $891-899$

[11] Kraemer D, Hu L, Muto A, Chen X, Chen G, Chiesa M. Photovoltaicthermoelectric hybrid systems: a general optimization methodology. Applied Physics Letters, 2008, 92 (24): 243503

[12] Mizoshiri M, Mikami M, Ozaki K. Thermal-photovoltaic hybrid solar generator using thin-film thermoelectric modules. Japanese Journal of Applied Physics, 2012, 51: 06FL07 
[13] Fleurial JP. Thermoelectric power generation materials: technology and application opportunities. Journal of the Minerals, Metals and Materials Society, 2009, 61(4): 79-85

[14] Van Sark W. Feasibility of photovoltaic-thermoelectric hybrid modules. Appllied Energy, 2011, 88(8): 2785-2790

[15]Hashim H, Bomphrey JJ, Min G. Model for geometry optimisation of thermoelectric devices in a hybrid PV-TE system. Renewable Energy, 2016, 87(1): $458-463$

[16]Bjørk R, Nielsen KK. The performance of a combined solar photovoltaic (PV) and thermoelectric generator (TEG) system. Solar Energy, 2015, 120: 187-194 [17]Lin WQ, Shih TM, Zheng JC, Zhang YF, Chen JC. Coupling of temperatures and power outputs in hybrid photovoltaic and thermoelectric modules. International Journal of Heat and Mass Transfer, 2014, 74: 121-127.

[18]Da Y, Xuan YM, Li Q. From light trapping to solar energy utilization: A novel photovoltaic-thermoelectric hybrid system to fully utilize solar spectrum. Energy, 2016, 95: 200-210

[19]Cui TF, Xuan YM, Li Q. Design of a novel concentrating photovoltaicthermoelectric system incorporated with phase change materials. Energy Conversion and Management. 2016, 112: 49-60

[20]Wang N, Han L, He HC, Park NH, Koumoto K. A novel high-performance photovoltaic-thermoelectric hybrid device. Energy \& Environmental Science. 2011, 4: 3676-3679. 
[21] Adham Makki, Siddig Omer, Yuehong Su, Hisham Sabir. Numerical investigation of heat pipe-based photovoltaic-thermoelectric generator (HP-PV/TEG) hybrid system. Energy Conversion and Management. Volume 112, 15 March 2016, Pages 274-287

[22] Deng YC, Zhao YH, Wang W, Quan ZH, Wang LC, Yu D. Experimental investigation of performance for the novel flat plate solar collector with micro-channel heat pipe array (MHPA-FPC). Applied Thermal Engineering, 2013, 54(2): 440-449

[23] Guiqiang Li, Gan Zhang, Wei He, Jie Ji, Song Lv, Xiao Chen, Hongbing Chen. Performance analysis on a solar concentrating thermoelectric generator using the micro-channel heat pipe array. Energy Conversion and Management 112 (2016) 191-198

[24] Li Guiqiang, Pei Gang, Su Yuehong, Ji Jie, Saffa B. Riffat. Experiment and simulation study on the flux distribution of lens-walled compound parabolic concentrator compared with mirror compound parabolic concentrator. Energy 58 (2013) 398-403

[25] Wei He, Gan Zhang, Guiqiang Li, Jie Ji. Analysis and discussion on the impact of non-uniform input heat flux on thermoelectric generator array. Energy Conversion and Management 98 (2015) 268-274

[26] G. Min, ZT measurements under large temperature differences, J. Electron. Mater 39 (9) (Mar. 2010) 1782-1785.

[27] G. Min, Thermoelectric module design under a given thermal input: theory and 
example, J. Electron. Mater 42 (7) (2013) 2239-2242.

[28] H. Hashim, J.J. Bomphrey, G. Min. Model for geometry optimisation of thermoelectric devices in a hybrid PV/TE system. Renewable Energy 87 (2016) $458-463$

[29] Bergman TL, Incropera FP, Lavine AS. Fundamentals of heat and mass transfer. John Wiley \& Sons; 2011.

[30] Guiqiang Li, Jie Ji, Gan Zhang, Wei He, Xiao Chen and Hongbing Chen. Performance analysis on a novel micro-channel heat pipe evacuated tube solar collector-incorporated thermoelectric generation. DOI: 10.1002/er.3589

[31] Adham Makki, Siddig Omer, Yuehong Su, Hisham Sabir. Numerical investigation of heat pipe-based photovoltaic-thermoelectric generator (HP-PV/TEG) hybrid system. Energy Conversion and Management 112(2016) 274-287 


\section{Figure lists}

Fig.1 Schematic diagram of the novel photovoltaic-thermoelectric system

Fig.2 Schematic of the heat transfer network of the new PV-TE system

Fig.3 TEG hot and cold side temperature at different solar radiation

Fig.4 Electrical efficiency of PV and TEG in PV-TE system at different solar radiation

Fig.5 System efficiency comparison between PV-TE and conventional PV at different solar radiation

Fig.6 TEG hot and cold side temperature at different wind speeds

Fig.7 Electrical efficiency of PV and TEG in PV-TE system at different wind speed

Fig.8 System efficiency comparison between PV-TE and conventional PV at different wind speeds

Fig.9 TEG hot and cold side temperature at different ambient temperature

Fig.10 Electrical efficiency of PV and TEG in PV-TE system at different ambient temperature

Fig.11 System efficiency comparison between PV-TE and conventional PV at different ambient temperatures

Fig.12 Efficiency comparison of PV, novel PV-TE and conventional PV-TE

Fig.13 Flow chart of the computation process for the PV-TE system

Fig.14 Electricity production comparison of PV, novel PV-TE and conventional PV-TE systems in Hefei

Fig.15 Pay-Back-Period of the novel PV-TE system 


\section{Table captions}

Table 1 The relative parameters in the PV-TE system

Table 2 Extra costs in novel PV-TE system

\section{Nomenclature}




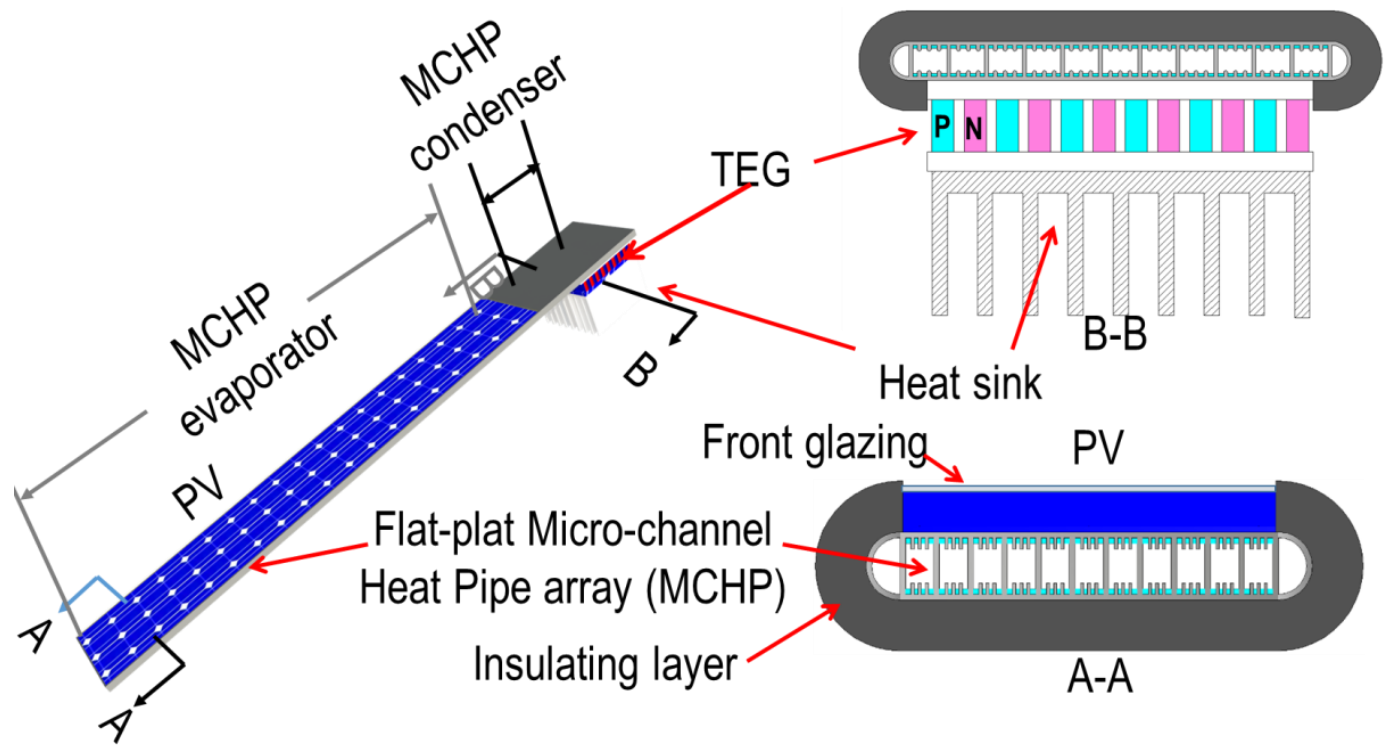

Fig.1 Schematic diagram of the novel photovoltaic-thermoelectric system

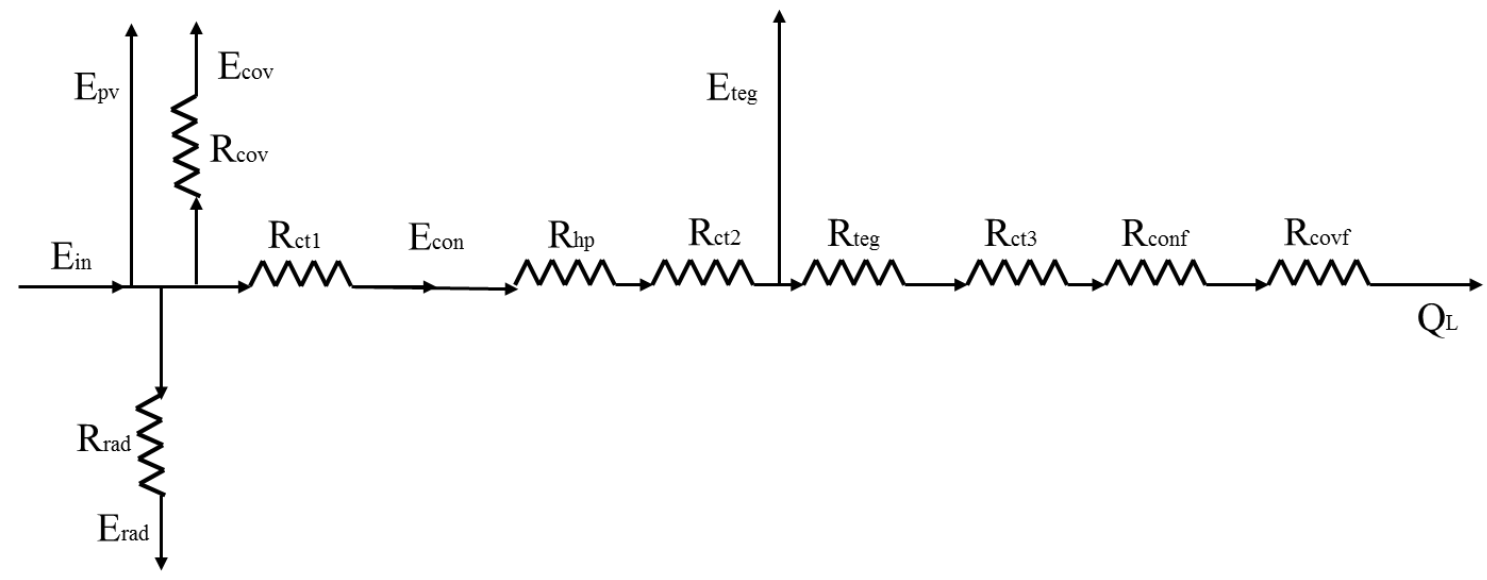

Fig.2 Schematic of the heat transfer network of the new PV-TE system 


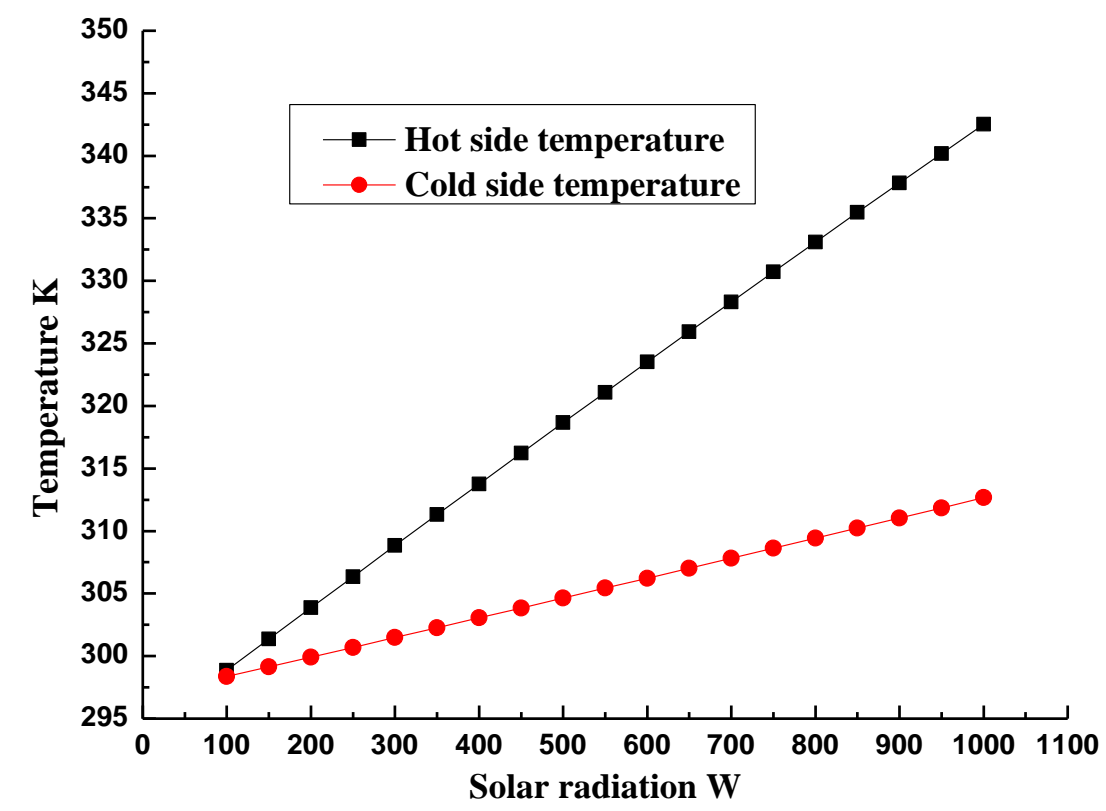

Fig.3 TEG hot and cold side temperature at different solar radiation

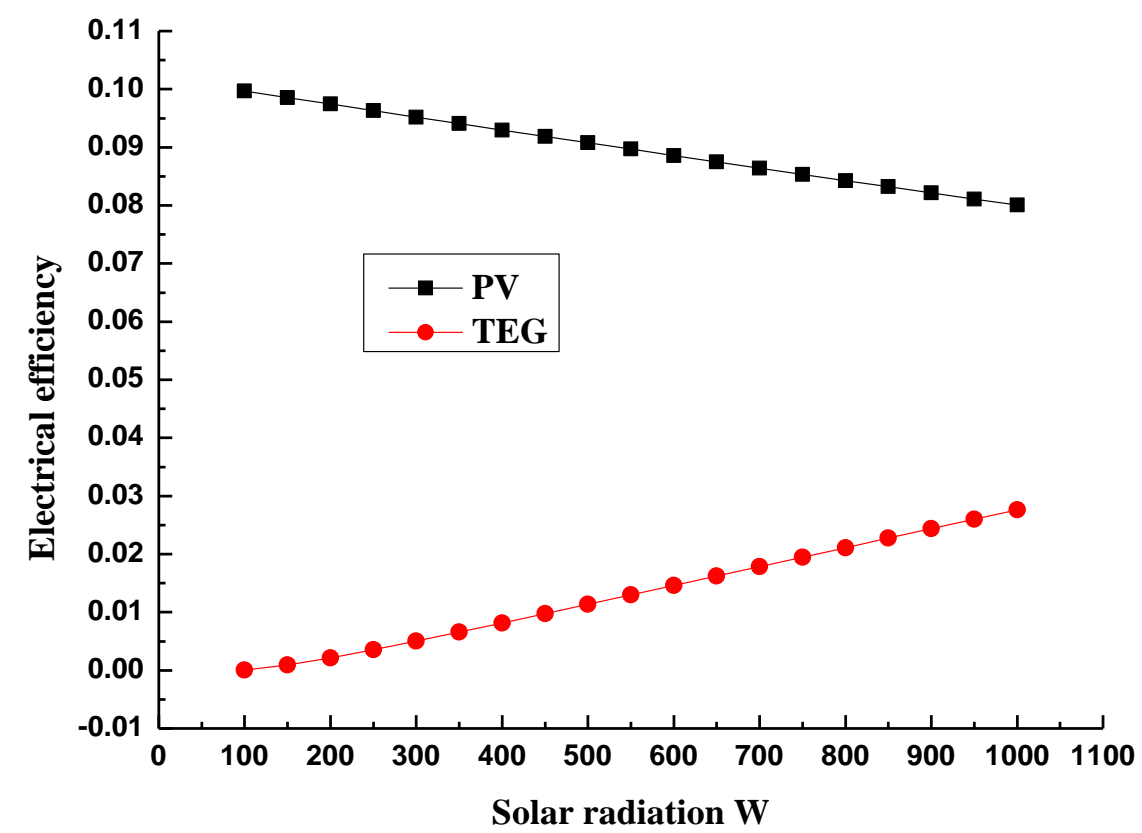

Fig.4 Electrical efficiency of PV and TEG in PV-TE system at different solar radiation 


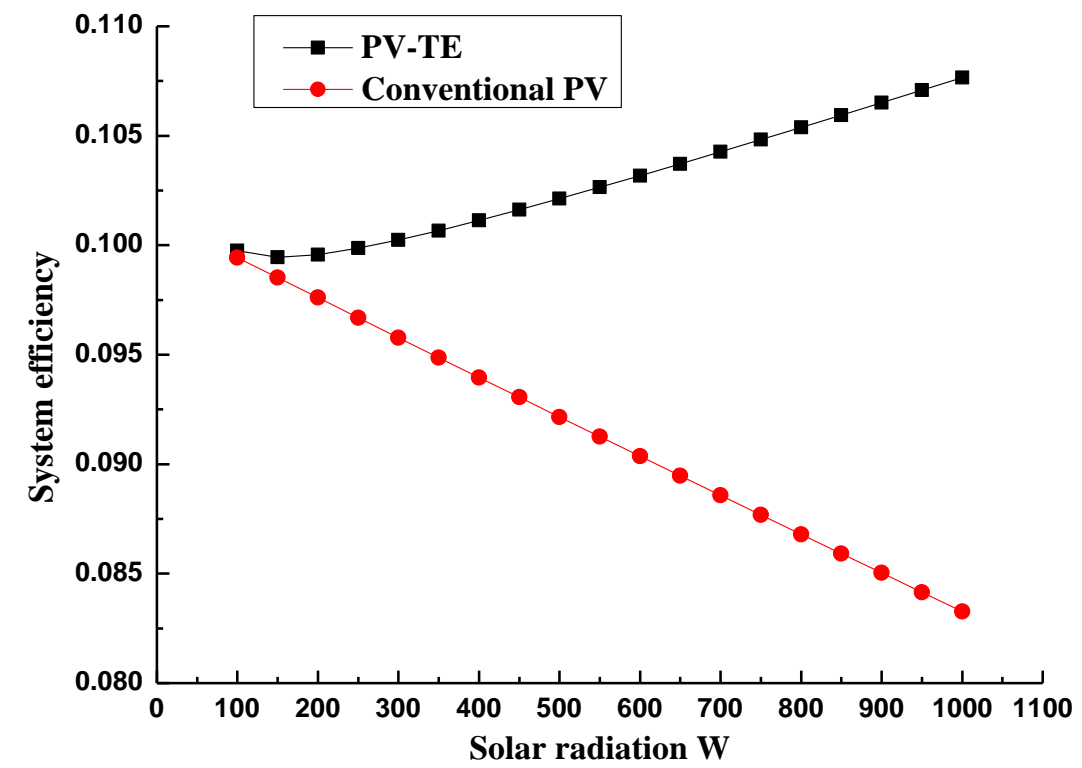

Fig.5 System efficiency comparison between PV-TE and conventional PV at different solar radiation

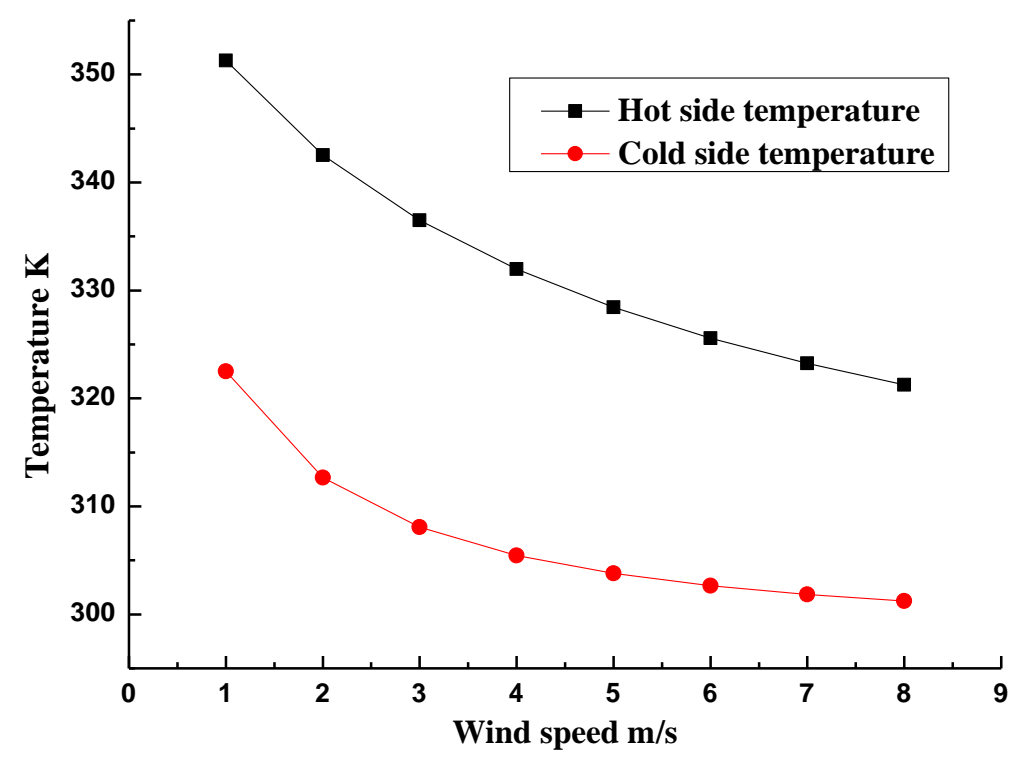

Fig.6 TEG hot and cold side temperature at different wind speeds 


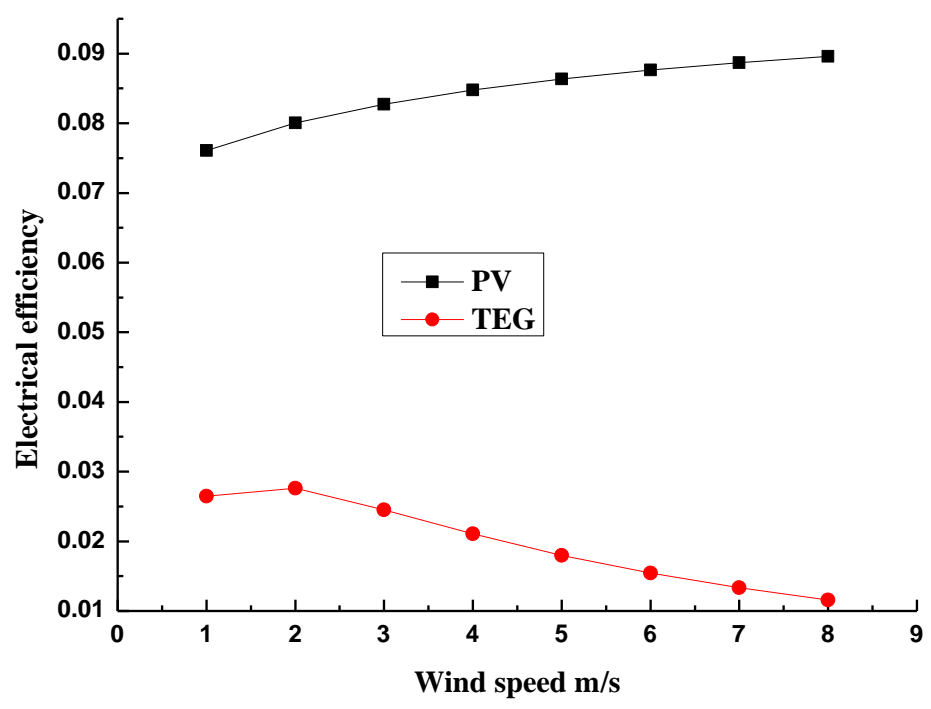

Fig.7 Electrical efficiency of PV and TEG in PV-TE system at different wind speed

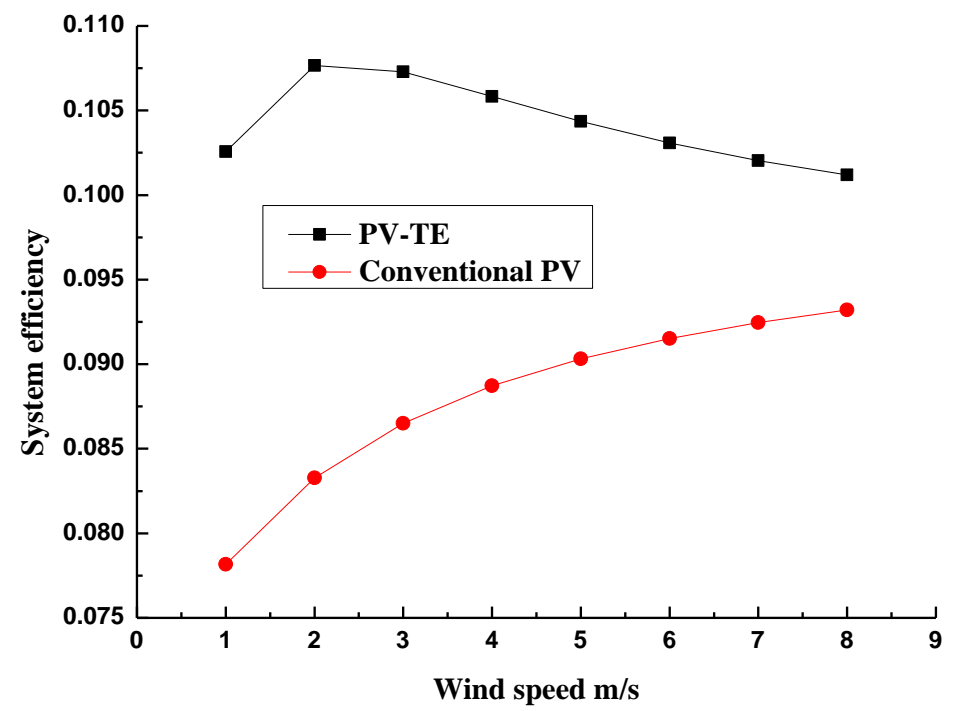

Fig.8 System efficiency comparison between PV-TE and conventional PV at different wind speeds 


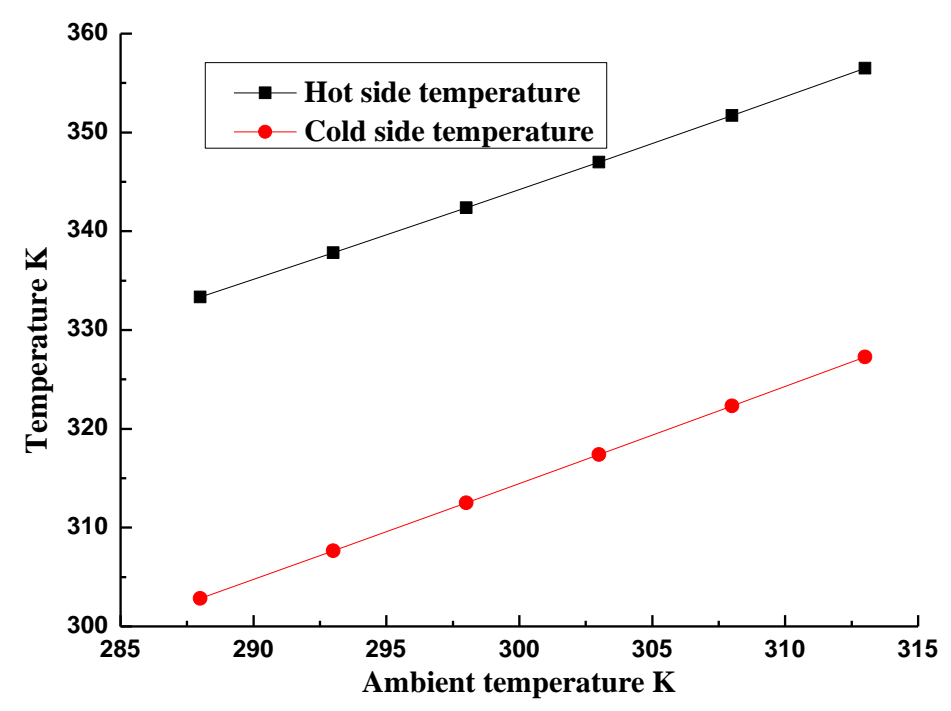

Fig.9 TEG hot and cold side temperature at different ambient temperature

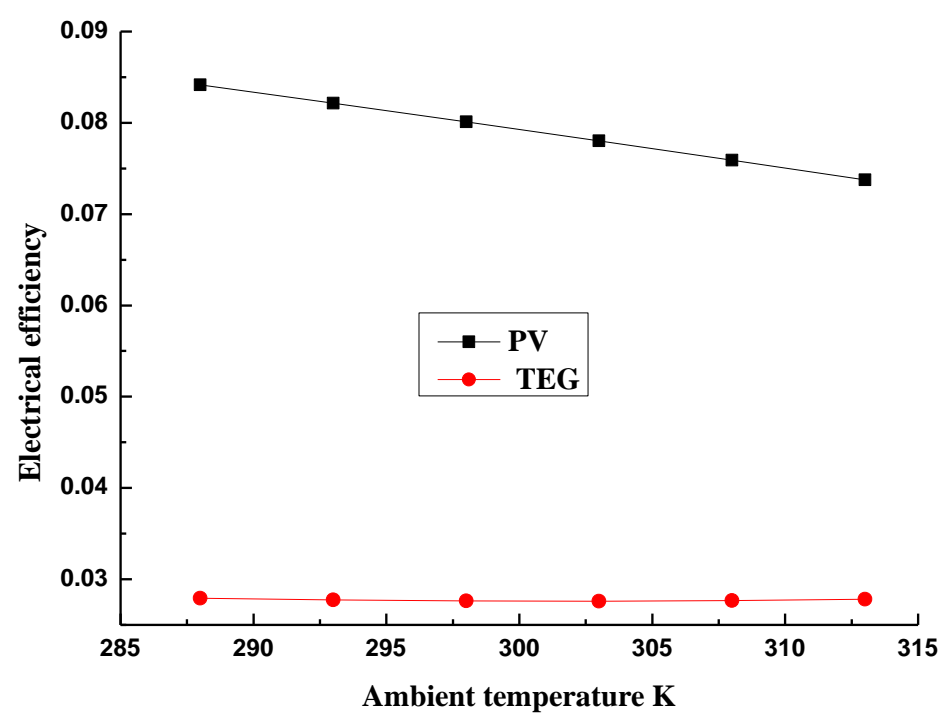

Fig.10 Electrical efficiency of PV and TEG in PV-TE system at different ambient temperature 


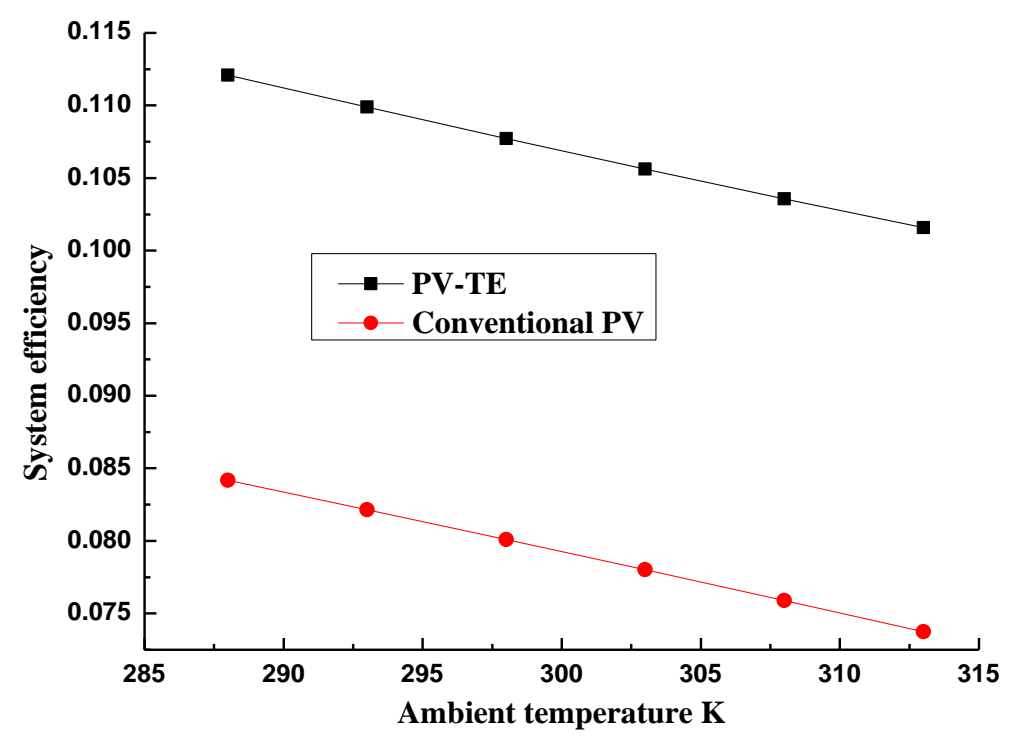

Fig.11 System efficiency comparison between PV-TE and conventional PV at different ambient temperatures

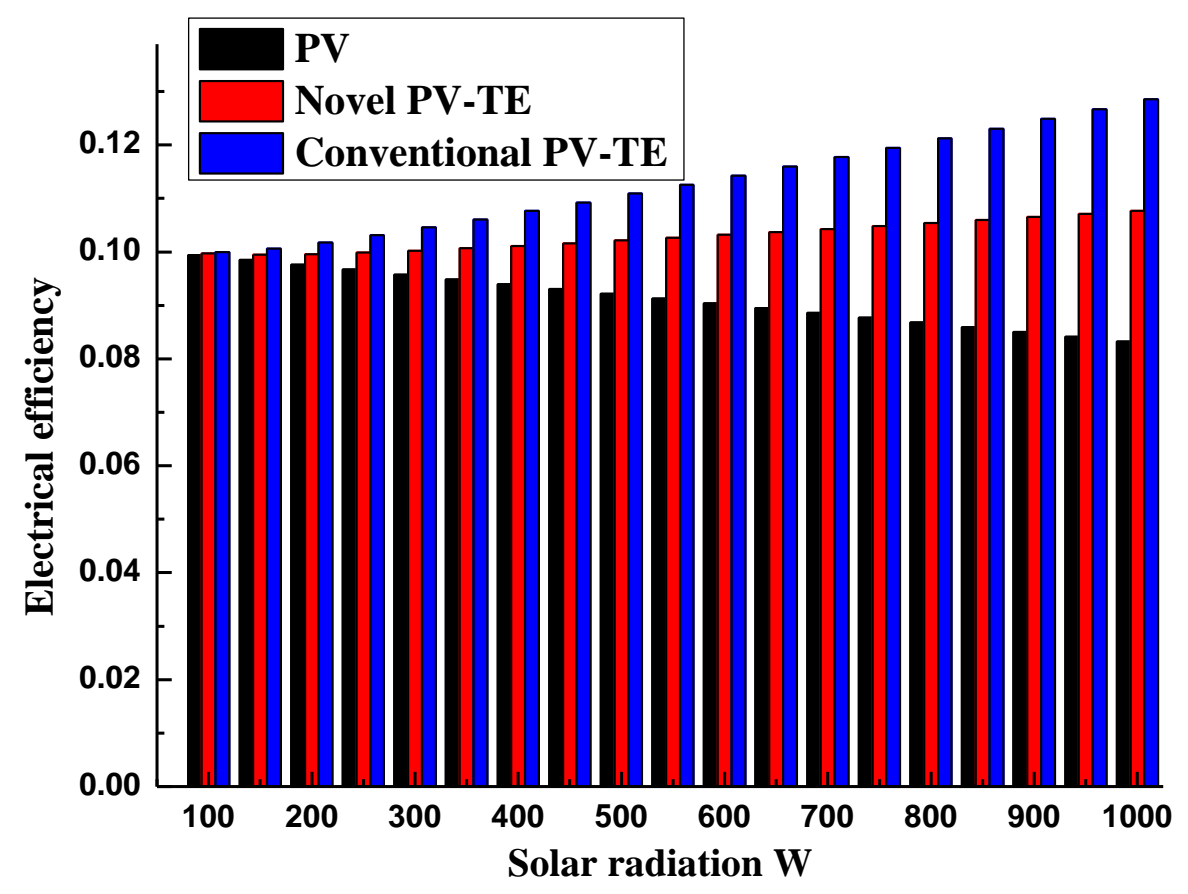

Fig.12 Efficiency comparison of PV, novel PV-TE and conventional PV-TE 


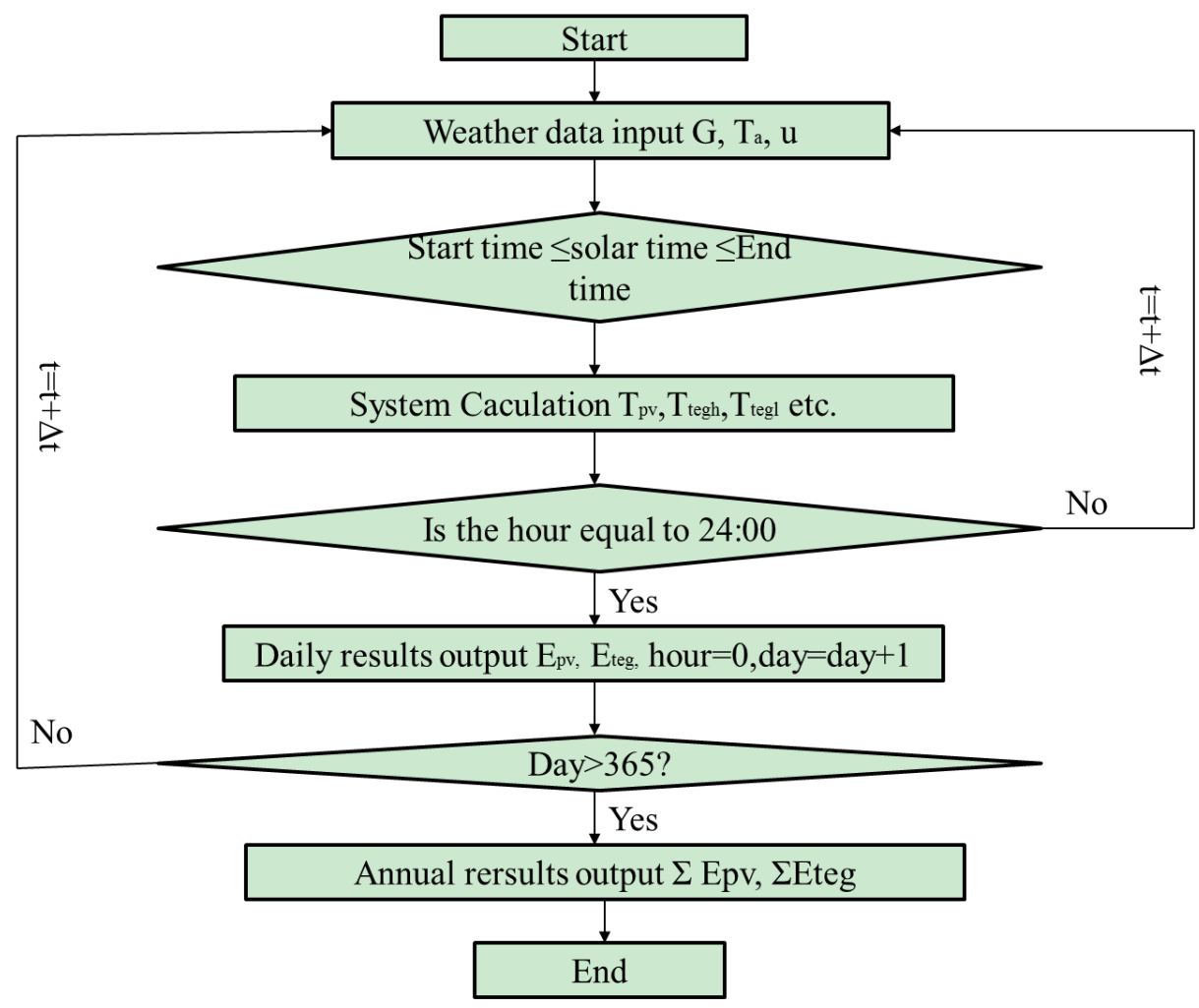

Fig.13 Flow chart of the computation process for the PV-TE system

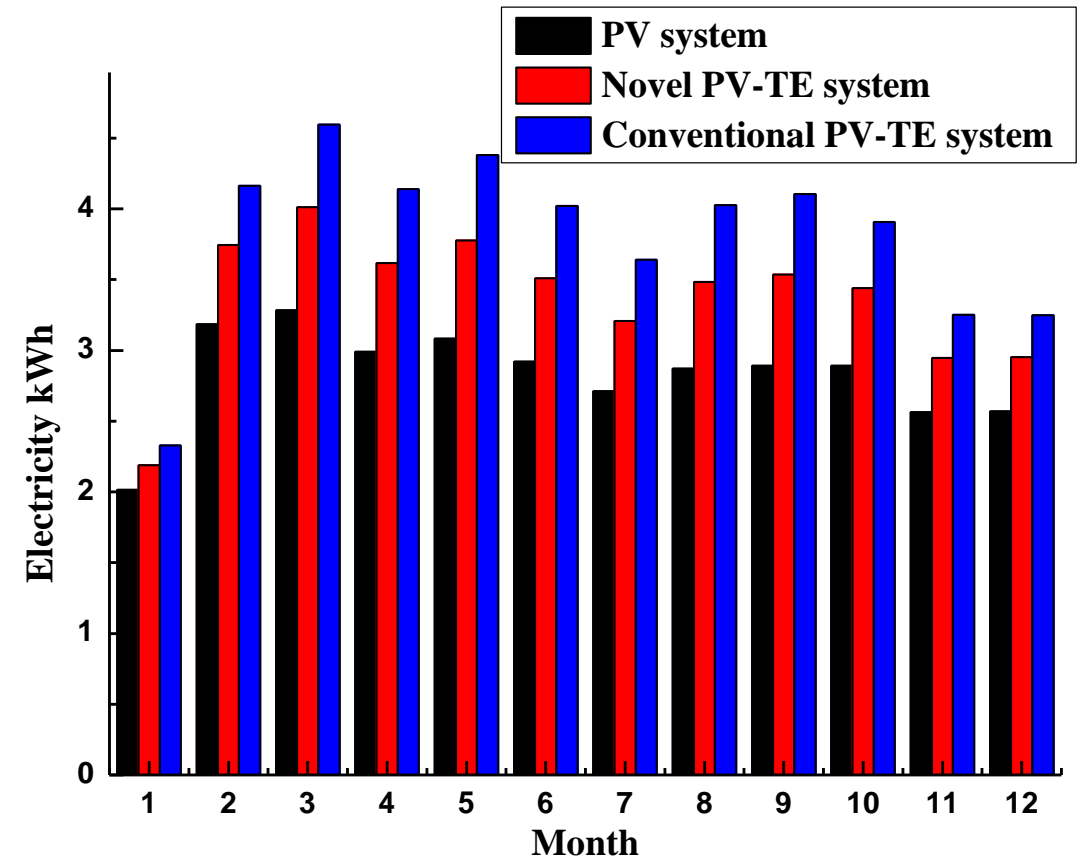

Fig.14 Electricity production comparison of PV, novel PV-TE and conventional PV-TE systems in Hefei 


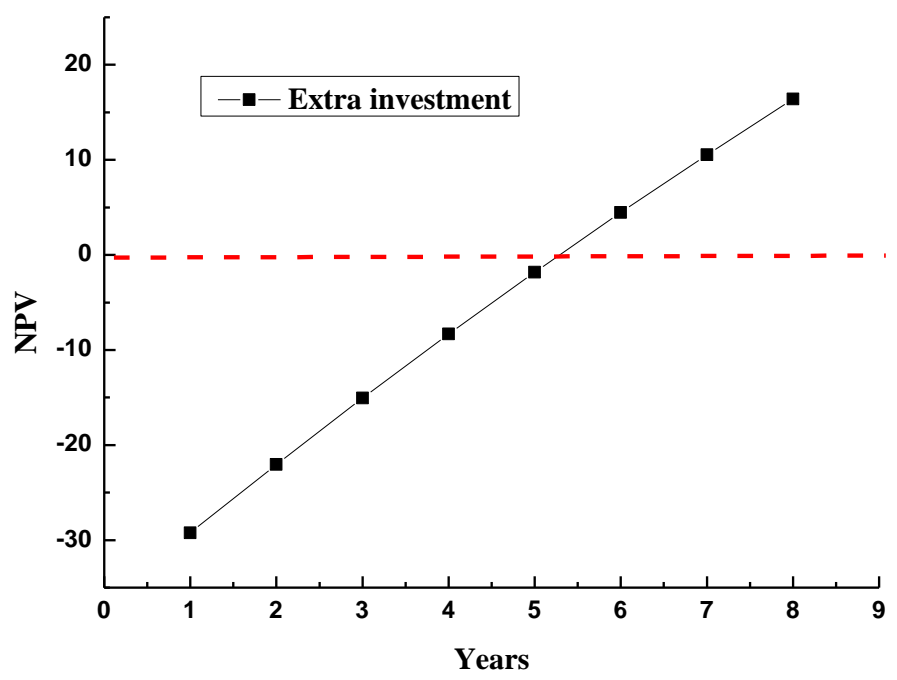

Fig.15 Pay-Back-Period of the novel PV-TE system 
Table 1 The relative parameters in the PV-TE system

\begin{tabular}{ll}
\hline \hline Parameter & Numerical \\
\hline PV & $1.2 * 0.18 \mathrm{~m}^{2}$ \\
Area & 0.09 \\
Transmittance of front glazing on PV $\tau_{\alpha}$ & 0.08 \\
Reflecance of front glazing on PV $\rho_{g}$ & 0.9 \\
Absorptivity of PV $\alpha$ & $14.2 \%$ \\
PV efficiency $\eta_{r}$ &
\end{tabular}

Thermal contact resistance between PV and heat pipe $R_{c t 1}$

$4 \times 10^{-4} \Omega$

Thermal contact resistance between PV and the
TEG $R_{c t 2}$
$1 \times 10^{-4} \Omega$

\section{Micro-channel heat pipe}

Thermal conductivity of heat pipe $K \quad 23000 \mathrm{~W} /(\mathrm{m} \cdot \mathrm{K})$

Length of the heat pipe $L_{h p} \quad 1.25 \mathrm{~m}$

Thermal contact resistance between TEG and heat sink $R_{c t 3} \quad 1 \times 10^{-4} \Omega$

\section{TEG}

Numbers of $\mathrm{P}$ or $\mathrm{N}$ junction $n_{\text {teg }}$

Cross-section area of one $\mathrm{P}$ or N junction $a_{\text {teg }} \quad 1 \times 10^{-8} \mathrm{~m}^{2}$

Seebeck coefficient $\alpha_{\text {teg }} \quad 1.35 \times 10^{-4} V / K$

Electrical resistivity of one $\mathrm{P}$ or $\mathrm{N}$ junction $r_{\text {teg }} \quad 3.35 \times 10^{-8} \Omega / \mathrm{m}$

Height of TEG ${ }_{\text {teg }} \quad 3.4 \times 10^{-3} \mathrm{~m}$

\section{Heat sink}


Height of the heat sink $\mathrm{H}$

Length of the heat sink $\mathrm{L}$

Cross section area of the heat sink $S_{1}$

Total area of the fins $S_{2}$
$1 \times 10^{-2} \mathrm{~m}$

$5 \times 10^{-2} \mathrm{~m}$

$1.2 \times 10^{-4} \mathrm{~m}^{2}$

$1.46 \times 10^{-2} \mathrm{~m}^{2}$

Table 2 Extra costs in novel PV-TE system

\begin{tabular}{llll}
\hline \hline Module & Micro-channel heat pipe & TEG & Heat sink \\
\hline Cost & $¥ 15.0$ & $¥ 22.0$ & $¥ 1.0$ \\
\hline \hline
\end{tabular}




\begin{tabular}{|c|c|c|c|}
\hline \multicolumn{4}{|c|}{ Nomenclature } \\
\hline$A$ & Area of PV & $R_{c t 1}$ & $\begin{array}{c}\text { Thermal contact resistance between } \\
\text { selective absorbing coating and heat } \\
\text { pipe } \mathrm{KW}^{-1}\end{array}$ \\
\hline$a_{\text {teg }}$ & $\begin{array}{l}\text { Cross-sectional area of a } \mathrm{P} \text { or } \mathrm{N} \text { leg } \\
\mathrm{m}^{2}\end{array}$ & $R_{c t 2}$ & $\begin{array}{c}\text { Thermal contact resistance between } \\
\text { heat pipe and the TEG } \mathrm{KW}^{-1}\end{array}$ \\
\hline$C_{f x}$ & Local friction coefficient & $\mathbf{R}_{c t 3}$ & $\begin{array}{c}\text { Thermal contact resistance between } \\
\text { TEG and heat sink } \mathrm{KW}^{-1}\end{array}$ \\
\hline$C_{p}$ & Specific heat of air $\mathrm{kJ} /(\mathrm{kgK})$ & $R_{f i n}$ & $\begin{array}{l}\text { Thermal resistance of the heat sink } \\
\qquad \mathrm{KW}^{-1}\end{array}$ \\
\hline$E_{c o n}$ & Heat flux via conduction $\mathrm{W}$ & $r_{\text {teg }}$ & $\begin{array}{l}\text { Electrical resistivity of } \mathrm{P} \text { or } \mathrm{N} \\
\text { junction } \Omega \bullet \mathrm{m}\end{array}$ \\
\hline$E_{\text {cov }}$ & Heat flux via convection $\mathrm{W}$ & $\operatorname{Re}$ & Reynolds number \\
\hline$E_{\text {in }}$ & $\begin{array}{c}\text { Solar energy absorbed by selective } \\
\text { absorbing coating W }\end{array}$ & $S t$ & Stanton number \\
\hline$E_{p v}$ & PV electrical output W & $S_{1}$ & $\begin{array}{l}\text { Cross section area of the heat sink } \\
\qquad \mathrm{m}^{2}\end{array}$ \\
\hline$E_{r a d}$ & Heat flux via radiation $\mathrm{W}$ & $S_{2}$ & Total area of the heat sink $\mathrm{m}^{2}$ \\
\hline$G$ & Solar radiation $\mathrm{W} / \mathrm{m}^{2}$ & $T_{a}$ & Temperature of ambient air $\mathrm{K}$ \\
\hline$h_{\mathrm{cov}}$ & $\begin{array}{l}\text { Coefficient of convection heat } \\
\text { transfer } \mathrm{W} /\left(\mathrm{m}^{2} \mathrm{~K}\right)\end{array}$ & $T_{h}$ & $\begin{array}{c}\text { Temperature of the evaporating side } \\
\text { of the heat pipe } K\end{array}$ \\
\hline$h_{\text {rad }}$ & $\begin{array}{l}\text { Coefficient of radiation heat } \\
\text { transfer } \\
\mathrm{W} /\left(\mathrm{m}^{2} \mathrm{~K}\right)\end{array}$ & $T_{\text {tegh }}$ & $\begin{array}{l}\text { The temperature of hot side of TEG } \\
\mathrm{K}\end{array}$ \\
\hline$I$ & Electrical current A & $T_{\text {tegl }}$ & $\begin{array}{c}\text { Temperature of the cold side of } \\
\text { TEG } K\end{array}$ \\
\hline$K$ & $\begin{array}{l}\text { Thermal conductivity of heat pipe } \\
\qquad \mathrm{Wm}^{-1} \mathrm{k}^{-1}\end{array}$ & $T_{1}$ & $\begin{array}{l}\text { Temperature of the condensate side } \\
\text { of the heat pipe } \mathrm{K}\end{array}$ \\
\hline$k_{\text {air }}$ & $\begin{array}{l}\text { Thermal conductivity of air } \\
\qquad \mathrm{Wm}^{-1} \mathrm{k}^{-1}\end{array}$ & $T_{p}$ & Temperature of absorbing coating $\mathrm{K}$ \\
\hline$k_{t e g}$ & $\begin{array}{l}\text { Thermal conductivity of TEG } \\
\qquad \mathrm{Wm}^{-1} \mathrm{~K}^{-1}\end{array}$ & $T_{s k y}$ & Temperature of sky $\mathrm{K}$ \\
\hline $\mathrm{L}$ & Length of the heat sink $\mathrm{m}$ & $u$ & Wind speed $\mathrm{m} / \mathrm{s}$ \\
\hline$L_{h p}$ & Length of heat pipe $\mathrm{m}$ & Greel & Letters \\
\hline$l_{\text {teg }}$ & Height of TEG $\mathrm{m}$ & $\alpha$ & Heat diffusivity $\mathrm{m}^{2} / \mathrm{s}$ \\
\hline$n_{\text {teg }}$ & Numbers of PN junction & $\alpha_{b}$ & Absorptivity of absorbing coating \\
\hline
\end{tabular}




\begin{tabular}{|c|c|c|c|}
\hline $\mathrm{Nu}$ & Nuselt number & $\alpha_{t e g}$ & Seebeck coefficient $\mathrm{VK}^{-1}$ \\
\hline $\operatorname{Pr}$ & Prandtl number & $\delta$ & $\begin{array}{l}\text { Stefan-Boltzmann constant } \\
\mathrm{Wm}^{-2} \cdot \mathrm{K}^{-4}\end{array}$ \\
\hline$Q_{\text {tegh }}$ & $\begin{array}{c}\text { Energy that passed in hot side of } \\
\text { the TEG W }\end{array}$ & $\varepsilon$ & Reflectivity of absorbing coating \\
\hline$Q_{\text {tegl }}$ & $\begin{array}{c}\text { Energy that passed out of cold side } \\
\text { of the TEG W }\end{array}$ & $\mu$ & Viscosity (dynamic) ${ }^{2}, \mathrm{~N} \cdot \mathrm{s} / \mathrm{m}^{2}$ \\
\hline$R_{\text {conf }}$ & $\begin{array}{l}\text { Resistance of the heat conduction } \\
\text { in heat } \operatorname{sink} \mathrm{KW}^{-1}\end{array}$ & $v$ & Kinematic viscosity, $\mathrm{m}^{2} / \mathrm{s}$ \\
\hline$R_{\operatorname{cov} f}$ & $\begin{array}{c}\text { Thermal resistance of convection } \\
\text { Heat transfer between heat sink and } \\
\text { ambient air } \mathrm{KW}^{-1}\end{array}$ & $\rho$ & Density of air $\mathrm{kg} / \mathrm{m}^{3}$ \\
\hline
\end{tabular}

